|| ISSN(online): 2589-8698 || ISSN(print): 2589-868X || International Journal of Medical and Biomedical Studies

Available Online at www.ijmbs.info

Volume 3, Issue 2; February: 2019; Page No. 13-19

PubMed (National Library of Medicine ID: 101738825)

Index Copernicus Value 2017: 40.03

\title{
“THE EFFECT OF ANTIVIRAL DRUG ON LIFE CYCLE OF HEPATITIS VIRUS B”
}

\section{Rupal Sengar ${ }^{1}$ Shivi Saxena ${ }^{1}$}

${ }^{1,2}$ Assistant Professor Faculty of Physiotherapy and Diagnostic, Jayoti Vidyapeeth Women's University, Jaipur, Rajasthan, India.

Article Info: Received 02 January 2019; Accepted 30 January. 2019

Cite this article as: Sengar, R., \& Saxena, S. (2019). "THE EFFECT OF ANTIVIRAL DRUG ON LIFE CYCLE OF

HEPATITIS VIRUS B". International Journal of Medical and Biomedical Studies, 3(2).

DOI: https://doi.org/10.32553/ijmbs.v3i2.87

Address for Correspondence: Rupal Sengar, Assistant Professor Faculty of Physiotherapy and Diagnostic, Jayoti Vidyapeeth Women's University, Jaipur, Rajasthan, India.

Conflict of interest: No conflict of interest.

\section{Abstract}

With up to 400 million influenced individuals around the world, constant hepatitis B infection (HBV) contamination is as yet a noteworthy medicinal services issue. Amid the most recent decade, a few novel helpful methodologies have been produced and assessed. In many locales of the world, interferon- $\alpha$, and nucleos(t)ide analogs (NUCs) are as of now affirmed. In spite of real enhancements, none of the current treatments is ideal since viral freedom is seldom accomplished. As of late, a superior comprehension of the HBV life cycle and the advancement of novel model frameworks of HBV disease have prompted the improvement of novel antiviral procedures and medication targets. This survey will concentrate on present and potential future medication focuses in the HBV life cycle and systems to balance the virus- have connection.

Key Words: hepatitis B virus, , interferon- $\alpha$, rcDNA, Antiviral agents.

\section{Introduction:}

After liver cell film connection to probably cellrelated heparan sulfate proteoglycans, the viral molecule ties explicitly to an obscure hepatocyte-explicit preS1-receptor ${ }^{5} \mathrm{Up}$ to this point, the exact system of viral section has not been clarified. Both, endocytosis and coordinate combination of the viral envelope with the plasma film have been proposed as potential pathways. In the wake of uncoating/discharge into the cytoplasm and transport of the nucleocapsid to the core, the halfway twofold stranded viral loosened up round DNA ( $r C D N A)$ is fixed by both viral and cell catalysts. In particular, the inadequate in addition to strand of the rCDNA is finished by the viral polymerase and in another progression the viral polymerase and
RNA-preliminaries utilized for DNA in addition to strand union is expelled by cell compounds ${ }^{6}$. In the end, covalently shut roundabout DNA (cccDNA) is shaped by covalent ligation of both DNA strands. Absence of cccDNA arrangement in non-human host cells, for example, hepatocytes from HBV transgenic mice proposes that have explicit components may direct this ligation procedure ${ }^{5}$. There is proof that each tainted cell contains 1- 50 cccDNA particles as remarkable episomal minichromosomes. As a replicative transitional of the HBV life cycle, cccDNA is critical for the diligence of HBV disease. Vitally, this is by all accounts genuine even in patients that show serologic proof of viral leeway ${ }^{7}$ Viral cccDNA fills in as a format for RNA blend. All popular RNA species are translated from the cccDNA utilizing the cell transcriptional 
apparatus. The viral DNA contains four noteworthy open perusing outlines

- The precore/center quality, coding for the nucleocapsid protein and for the discharged, non-auxiliary, precore protein, the HBeAg;
- The polymerase quality coding for the turn around transcriptase, RNase $\mathrm{H}$ and the terminal protein areas;

- The PreS1/L-, PreS2/M-and Surface/Squality, coding for the three envelope proteins; and the $X$ quality, coding for the administrative $X$-protein ${ }^{5}$

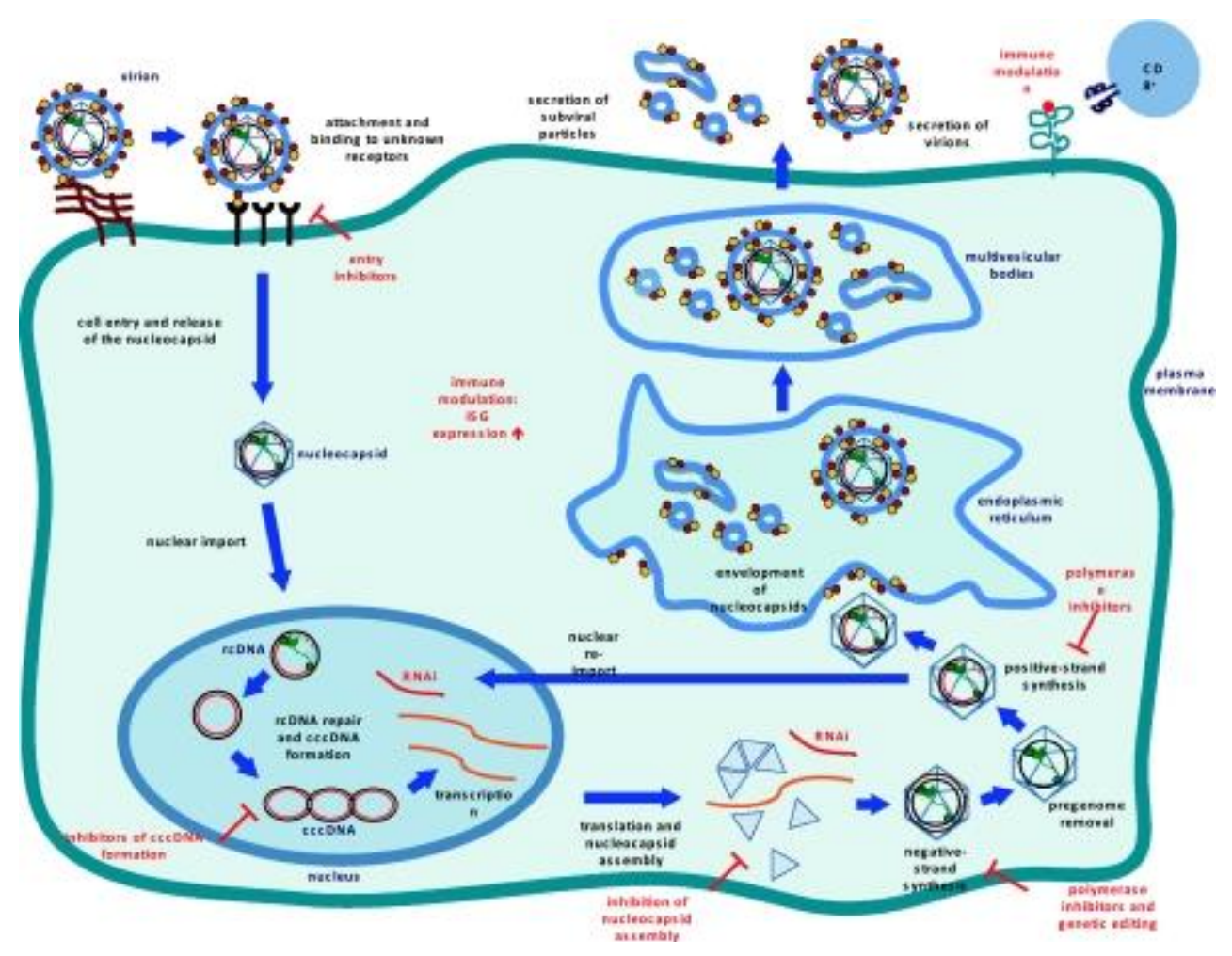

Figure 1: Life cycle of hepatitis Bvirus)

containing nucleocapsids are discharged into the cytoplasm and transported to the core. In the core, the rcDNA is fixed to frame cccDNA. The cccDNA is interpreted into subgenomic RNA (sgRNA) and pregenomic RNA (pgRNA). The pgRNA is encapsidated together with the $P$ protein. Inside the nucleocapsid, the pgRNA is turn around interpreted into negative-strand DNA. rCDNA is created by in addition to strand blend from the negative-strand DNA. The nucleocapsids are either re-imported to the core for cccDNA enhancement or encompassed and discharged by means of the endoplasmic reticulum (ER). Medication focuses inside the HBV life cycle and immunomodulatory approaches are delineated in red in Fig. Fig. $1^{5}$
After atomic fare, the pgRNA is converted into the center protein and the viral polymerase. The sgRNA is converted into the administrative $X$ protein and the three envelope proteins. Self-get together of the RNA-containing viral nucleocapsid happens by means of complex development of the pgRNA with the center protein and the polymerase. In the cytoplasm, RNA-containing nucleocapsids experience a development procedure to DNA containing nucleocapsids by turn around translation of the pgDNA. The invert transcriptase needs editing action; accordingly, changes of the viral genome are incessant and result in the concurrence of hereditarily unmistakable viral species in contaminated people (quasispecies). 
In the HBV life cycle, the DNA containing nucleocapsids satisfy two capacities. To begin with, they can be either re-brought into the core to frame extra cccDNA or second, they can be encompassed for emission by means of the ER. In the wake of growing into the ER lumen, the envelope proteins are discharged by the cell either as little, non-irresistible subviral circular or filamentous particles (SVPs) of $22 \mathrm{~nm}$ breadth or as irresistible virions of $42 \mathrm{~nm}$ (Dane particles). Normally, the non-irresistible SVPs are created in a 1,000-to 1,000,000-overlay overabundance over virions.

\section{MATERIAL AND METHODS}

Materials and Methods The American Association for the Study of Liver Diseases (AASLD) HBV rule strategy and composing boards of trustees built up a convention from the earlier for this deliberate survey. The announcing of this survey pursues the guidelines set in the Preferred Reporting Items for Systematic Reviews and Meta-investigation statement. ${ }^{5}$ The board of trustees recognized and built up a convention for seven key Population Intervention Comparison Outcome questions. The results of intrigue were clinical results (cirrhosis, liver decompensation, hepatocellular carcinoma [HCC], and allcause mortality); in any case, when such result information were inaccessible, surrogate (middle of the road) results were looked for, explicitly toughness of $\mathrm{HBeAg}$ seroconversion, loss of hepatitis B surface (HBsAg), long haul concealment of HBV DNA, and standardization of ALT.

inclusion Criteria: We included randomized controlled preliminaries (RCTs) and controlled observational examinations that selected grownups 18 years of age determined to have incessant HBV contamination who gotten antiviral treatment.

Exclusion Criteria: We rejected investigations that included patients with intense HBV disease; patients who were pregnant; patients co infected with hepatitis $\mathrm{C}$ or $\mathrm{D}$ or human immunodeficiency infection; patients getting corticosteroids, chemotherapy, or immunosuppressive treatment; transplant beneficiaries; and hemodialysis patients, just as concentrates without control or examination gatherings. Supporting Table S1 abridges the incorporation and avoidance criteria for each key inquiry.

An accomplished Mayo Clinic curator directed an extensive pursuit of Medline In-Process and Other Non-Indexed Citations, MEDLINE, EMBASE, Cochrane Central Register of Controlled Trials, Cochrane Database of Systematic Reviews, and Scopus from mid 1988 to September 16, 2014.

Controlled vocabulary enhanced with watchwords was utilized to scan for similar investigations of antivirals for constant hepatitis B. No dialect confinements were utilized. Individuals from the AASLD HBV rule philosophy and composing panels recognized extra examinations.

Study Selections: Two analysts autonomously screened titles and digests for potential qualification utilizing an online reference the executives framework (Distiller SR; Evidence Partners, Inc.). Full messages of the included digests were recovered and screened in copy. Differences were settled by looking for accord or assertion by a third commentator. Interreviewer assention (kappa) was determined amid each screening dimension to evaluate understanding between analysts. For Population Intervention Comparison Outcome addresses where no examinations meeting the predefined criteria were discovered, the AASLD HBV rule technique board of trustees performed manual scans for uncontrolled observational investigations. Information from these examinations were abridged narratively and all in all reliable with low-quality proof.

\section{RESULT AND DISCUSSION}

Information was finished utilizing an institutionalized, directed frame. We extricated information on study qualities, persistent attributes, intercession subtleties, and results of intrigue. 
Methodological Quality and Risk of Bias Assessment: We utilized the Cochrane Risk of Bias evaluation apparatus and changed Newcastle-Ottawa Scale to survey the danger of predisposition in RCTs and observational investigations, separately. Nature of proof (i.e., sureness in the appraisals) was assessed utilizing the Grading of Recommendations Assessment, Development, and Evaluation approach. Criteria used to assess nature of proof were danger of predisposition, backhandedness (surrogate results), imprecision (wide certainty interims), irregularity (heterogeneity), and production bias. $^{6}$

Statistical Analysis: For dichotomized results, we determined hazard proportions (RRs) and 95\% certainty interims $(95 \% \mathrm{Cl})$ utilizing binomial dissemination. We at that point pooled the logchanged RRs utilizing the DerSimonian and Laird arbitrary impacts models and evaluated heterogeneity utilizing the Mantel-Haenszel demonstrate. To quantify the general heterogeneity over the included investigations, we determined the 12 measurement, where 12 $>50 \%$ recommends a high level of heterogeneity. Every single factual investigation was directed utilizing STATA, adaptation 13 (StataCorp LP, College Station, TX).

To investigate heterogeneity, we directed subgroup examination for studies selecting patients with further developed liver ailment; we performed stratified investigation for the accompanying gatherings: repaid cirrhosis, decompensated cirrhosis, intense on unending liver disappointment, and extreme intense intensifications of perpetual hepatitis $B$.

We investigated the effect of production inclination utilizing the Egger relapse asymmetry test and developing channel plots if an adequate number of studies (>20) per result was accessible and heterogeneity was low. ${ }^{7}$ Results A sum of 73 thinks about were incorporated.

The normal weighted kappa for study choice was 0.78 . Controlled examinations that detailed the results of intrigue were accessible for inquiries 1 ,
2,3 , and 5. Uncontrolled investigations that are significant to questions 4,6 , and 7 are outlined in Supporting Information. Supporting

Forty-two examinations analyzed antiviral treatment versus control and 18 considers looked at one antiviral specialist versus another. Adequacy of Antiviral Therapy Compared to Control in Patients With Chronic Hepatitis B Infection. Among 42 thinks about looking at antiviral treatment versus control in 62,731 patients, 16 studies8-23 analyzed IFN versus no treatment, 16 studies24-39 thought about lamivudine versus no treatment, seven studies28,40-45 analyzed entecavir versus no treatment, one investigation each analyzed telbivudine $^{9}$ and tenofovir 10 versus fake treatment, and three studies thought about an assortment of oral antiviral versus no treatment. Eleven examinations enlisted just patients with repaid cirrhosis, five investigations selected just patients with intense on unending liver disappointment, two examinations selected just patients with decompensated liver malady, three investigations selected just patients with extreme intense intensifications of constant hepatitis $B$, and 21 thinks about selected patients with stable incessant hepatitis $B$

Danger of inclination appraisal for RCTs was low to direct as two of the included RCTs announced the randomization strategy, two revealed utilization of portion camouflage, and six detailed the blinding technique utilized. The majority of the observational investigations were at high danger of inclination because of absence of clear depiction of the choice procedure of the populace and lacking introduction and result ascertainment.

In seven RCTs8,23-25,29,33,46 including 3463 subjects with a mean follow-up of 28 months, altogether diminished the general danger of decompensated liver infection (one RCT, RR 5 $0.4,95 \% \mathrm{Cl} 0.3-0.7$ ) and cirrhosis (one RCT, RR 5 $0.4,95 \% \mathrm{Cl} 0.2-0.8)$. No critical contrasts were found taking all things together reason mortality (four RCTs, RR 5 0.5, 95\% Cl 0.2-1.3, 125 72.9\%) 
or HCC occurrence (three RCTs, RR $50.6,95 \% \mathrm{Cl}$ 0.3-1.1, $1250 \%$ ). The nature of the proof was low to direct. One RCT29 analyzed unfriendly occasions including demise and decompensation as results, yet no occasions were seen in either the intercession or the control gathering.

In 35 observational examinations including 59,201 patients with a mean follow-up of 60 months, meta-investigation demonstrated that antiviral treatment versus control diminished the danger of HCC (23 considers, RR $50.5,95 \% \mathrm{Cl}$ $0.4-0.7,12587.4 \%$ ), all-cause mortality (23 contemplates, RR $50.6,95 \% \mathrm{Cl} 0.5-0.8,125$ 92.3\%), and cirrhosis (four investigations, RR 5 $0.6,95 \% \mathrm{Cl} 0.4-0.8,1250 \%$ ) however did not altogether decrease the danger of decompensated liver ailment (six examinations, RR 5 0.7, 95\% Cl 0.3-1.9, I2 5 96.5\%) when contrasted with untreated controls. The nature of this proof generally speaking was low; be that as it may, these examinations included extensive quantities of patients with long span of development, yielding exact and restricted 95\% Cls.

Viability of antiviral treatment contrasted with control in the subgroup with stable endless hepatitis $B$. Of the 21 ponders that enlisted patients with stable unending hepatitis B, $0 \%$ $91 \%$ of the 54,719 patients included had remunerated cirrhosis. Decrease in danger of decompensated cirrhosis was appeared just a single RCT and decrease in HCC in 11 observational examinations. No examinations showed decrease in allcause mortality.

Viability of Antiviral Therapy Compared to Control in Patients With Chronic HBV Infection and Compensated Cirrhosis. In one RCT25 enlisting 222 patients with cirrhosis and a followup of 53 months, lamivudine versus control decreased all-cause mortality (RR $50.1,95 \% \mathrm{Cl}$ $0.1-0.3$, moderatequality proof).

In 10 observational examinations including patients with remunerated cirrhosis (mean follow-up 60 months), antiviral treatment diminished the danger of HCC (10 examines, RR 5
0.6, 95\% Cl 0.4-0.8, $12536.3 \%$ ), decompensated liver malady (two investigations, RR $50.5,95 \% \mathrm{Cl}$ $0.2-0.9,12567.2 \%)$, and all-cause mortality (three examinations, RR 5 0.5, 95\% Cl 0.4-0.6, 12 $50 \%)$.

\section{CONCLUSION:}

Using of antiviral drug on life cycle of HBAs, While entecavir and tenofovir have powerful antiviral movement, a few patients have relentless viremia in spite of being follower to prescription. This is increasingly normal among HBeAg-positive patients with high standard serum HBV DNA. Studies looking at proceeding with entecavir or tenofovir monotherapy as opposed to including a second antiviral specialist in patients with steady viremia were not found. Observational investigations of patients who proceeded with entecavir or tenofovir monotherapy demonstrated that most patients at last

\section{REFERENCES:}

1. Dienstag JL. Hepatitis B virus infection. N Engl J Med. 2008;359(14):1486-1500. doi: 10.1056/NEJMra0801644.

2. Thimme R, Blum HE. (Therapy of hepatitis B). Praxis (Bern 1994) 2006;95(36):1383138.

3. ZF SeegerC, Mason WS. Hepadnaviruses. 5. Philadelphia: Lippincott, Williams and Wilkins; 2007

4. Stein LL, Loomba R. Drug targets in hepatitis B virus infection. Infect Disord Drug Targets. 2009;9(2):105-116.

5. Urban S, Schulze A, Dandri M, Petersen J. The replication cycle of hepatitis $B$ virus. J Hepatol. 2010;52(2):282-284. doi:10.1016/j.jhep.2009.10.031.

6. Nassal M. Hepatitis B viruses: reverse transcription a different way. Virus Res. 2008;134(1-2):235-249. doi:10.1016/j.virusres.2007.12.024.

7. Balsano C, Alisi A. Viral hepatitis B: established and emerging therapies. Curr Med Chem. 2008;15(9): 930-939. doi:10.2174/092986708783955383. 
8. Ott JJ, Stevens GA, Groeger J, Wiersma ST. Global epidemiology of hepatitis B virus infection: new estimates of age-specific HBsAg seroprevalence and endemicity. Vaccine 2012;30:2212-2219.

9. Wasley A, Kruszon-Moran D, Kuhnert W, Simard EP, Finelli L, McQuillan G, et al. The prevalence of hepatitis $B$ virus infection in the United States in the era of vaccination. $\mathrm{J}$ Infect Dis 2010;202:192- 201.

10. Kowdley KV, Wang CC, Welch S, Roberts $\mathrm{H}$, Brosgart CL. Prevalence of chronic hepatitis $B$ among foreign-born persons living in the United States by country of origin. HEPATOLOGY 2012;56:422-433.

11. Lok AS, McMahon BJ. Chronic hepatitis B. HEPATOLOGY 2007;45:507- 539.

12. Moher D, Liberati $A$, Tetzlaff J, Altman DG. Preferred reporting items for systematic reviews and meta-analyses: the PRISMA statement. PLoS Med 2009;6:e1000097.

13. Murad $\mathrm{MH}$, Montori VM, Ioannidis JP, Jaeschke R, Devereaux PJ, Prasad K, et al. How to read a systematic review and metaanalysis and apply the results to patient care: users' guides to the medical literature. JAMA 2014;312:171-179.

14. Sterne JA, Sutton AJ, loannidis JP, Terrin N, Jones DR, Lau J, et al. Recommendations for examining and interpreting funnel plot asymmetry in meta-analyses of randomised controlled trials. BMJ 2011;343: d4002.

15. Anderson MG, Harrison TJ, Alexander G, Zuckerman AJ, MurrayLyon IM. Randomised controlled trial of lymphoblastoid interferon for chronic active hepatitis B. Gut 1987;28:619-622.

16. International Interferon-alpha Hepatocellular Carcinoma Study Group. Effect of interferon-alpha on progression of cirrhosis to hepatocellular carcinoma: a retrospective cohort study. Lancet 1998;351:1535-1539.

17. Lin $\mathrm{S}-\mathrm{M}, \mathrm{Yu} \mathrm{M}-\mathrm{L}$, Lee $\mathrm{C}-\mathrm{M}$, Chien R-N, Sheen IS, Chu C-M, et al. Interferon therapy in $\mathrm{HBeAg}$ positive chronic hepatitis reduces progression to cirrhosis and hepatocellular carcinoma. J Hepatol 2007;46:45- 52.

18. Truong BX, Seo $Y$, Kato $M$, Hamano $K$, Ninomiya $T$, Katayama $M$, et al. Long-term follow-up of Japanese patients with chronic hepatitis B treated with interferon-alpha. Int J Mol Med 2005;16:279-284.

19. Tangkijvanich $P$, Thong-ngam $D$, Mahachai $V$, Kladchareon N, Suwangool P, Kullavanijaya P. Long-term effect of interferon therapy on incidence of cirrhosis and hepatocellular carcinoma in Thai patients with chronic hepatitis B. Southeast Asian J Trop Med Public Health 2001;32:452-458.

20. Papatheodoridis GV, Manesis E, Hadziyannis SJ. The long-term outcome of interferon-alpha treated and untreated patients with HBeAgnegative chronic hepatitis B. J Hepatol 2001;34:306-313.

21. Niederau $C$, Heintges $T$, Lange $S$, Goldmann G, Niederau CM, Mohr L, et al. Long-term follow-up of HBeAg-positive patients treated with interferon alfa for chronic hepatitis B. N Engl J Med 1996;334:14221427.

22. Lin SM, Tai DI, Chien RN, Sheen IS, Chu CM, Liaw YF. Comparison of long-term effects of lymphoblastoid interferon alpha and HEPATOLOGY, Vol. 63, No. 1, 2016 LOK ET AL. 303 recombinant interferon alpha2a therapy in patients with chronic hepatitis B. J Viral Hepat 2004;11:349-357.

23. Benvegnu L, Chemello L, Noventa F, Fattovich G, Pontisso P, Alberti A. Retrospective analysis of the effect of interferon therapy on the clinical outcome of patients with viral cirrhosis. Cancer 1998;83:901-909.

24. Tong MJ, Blatt LM, Tyson KB, Kao VWC. Death from liver disease and development of hepatocellular carcinoma in patients with chronic hepatitis B virus infection: a prospective study. Gastroenterol Hepatol (Que) 2006;2:41-47.

25. Di Marco V, Lo lacono O, Camma C, Vaccaro A, Giunta M, Martorana G, et al. 
The long-term course of chronic hepatitis B. HEPATOLOGY 1999;30:257-264.

26. Brunetto MR, Oliveri F, Coco B, Leandro G, Colombatto $\mathrm{P}$, Gorin JM, et al. Outcome of anti-HBe positive chronic hepatitis $B$ in alphainterferon treated and untreated patients: a long term cohort study. J Hepatol 2002;36:263-270.

27. Mahmood S, Niiyama G, Kamei A, Izumi A, Nakata $\mathrm{K}$, Ikeda $\mathrm{H}$, et al. Influence of viral load and genotype in the progression of hepatitis B-associated liver cirrhosis to hepatocellular carcinoma. Liver Int 2005;25:220-225.
28. Ikeda K, Saitoh S, Suzuki Y, Kobayashi M, Tsubota A, Fukuda $M$, et al. Interferon decreases hepatocellular carcinogenesis in patients with cirrhosis caused by the hepatitis B virus: a pilot study. Cancer 1998;82: 827-835.

29. Fattovich G, Giustina G, Realdi G, Corrocher R, Schalm SW. Longterm outcome of hepatitis B e antigen-positive patients with compensated cirrhosis treated with interferon alfa. HEPATOLOGY 1997;26:1338- 1342. 